\title{
A retomada de compromissos históricos aos 30 anos da ANPEd
}

\author{
Luiz Antônio Cunha
}

Universidade Federal do Rio de Janeiro, Programa de Pós-Graduação em Educação

A metáfora da semente que germina parece-me sugestiva para este momento de celebração dos 30 anos da Associação Nacional de Pós-Graduação e Pesquisa em Educação (ANPEd): um grão que, ao encontrar condições adequadas de solo e clima, desenvolve-se e dá frutos. Não vou exagerar essa imagem, pois o desenvolvimento de qualquer semente está predeterminado. O que planta alguma pode fazer, uma associação, como a ANPEd, pode e deve: reagir sobre as condições de nascimento e desenvolvimento para seguir os caminhos definidos pelos associados em seus compromissos - os históricos e os conjunturais.

E por falar em semente, vejamos como a ANPEd foi plantada.

O solo da entidade foi o processo de expansão e diferenciação do campo educacional no Brasil, processo que se desenvolveu desde o fim do Estado Novo, acelerou-se na década de 1950 e, mais ainda, nas de 1960 e 1970.

No ensino superior federal, a reforma de 1968 ligou a pós-graduação, recém-institucionalizada, à carreira docente, fazendo dos títulos de mestre e de doutor requisitos de ingresso e de progressão. As ins- tituições estaduais logo seguiram essa diretiva. No setor privado, intensificou-se o crescimento de instituições de ensino, atraídas pelo promissor mercado de candidatos a diploma e alimentadas pelos subsídios governamentais, diretos e indiretos.

Com o aumento da oferta de diplomados, caíram o valor econômico e o valor simbólico dos diplomas de graduação, mais numas especialidades do que noutras. A recuperação desses valores foi buscada nos mais raros diplomas de mestre e de doutor - também por essa via, a pós-graduação expandiu-se, num leque que se abriu para mais e mais áreas.

Normatizando e apoiando financeiramente a expansão da pós-graduação estava a Coordenação de Aperfeiçoamento de Pessoal de Nível Superior (CAPES), agência governamental que refez sua vocação para dedicar-se a esse novo nível de ensino, complementando o Conselho Nacional de Desenvolvimento Científico e Tecnológico $(\mathrm{CNPq})$ ou competindo com ele.

Os programas de pós-graduação foram criados nas universidades e em outras instituições como verdadeiros enclaves, pilotados pelas agências governamentais de fomento, convenientemente protegidos das 
interferências dos departamentos, das faculdades e das próprias reitorias. Com isso, bons programas defenderam-se da mediocridade reinante à sua volta. E programas ruins puderam manter-se a salvo dos apelos de melhoria provenientes do seu entorno.

Foi nesse contexto que surgiram as associações de programas de pós-graduação. A CAPES pretendia dispor de uma associação de programas para cada área específica, que funcionasse como relé político-administrativo, capaz de intermediar suas relações institucionais.

Na grande área de humanas, a primeira associação desse tipo foi a ANPEC, da Economia, em 1973. Em 1977, veio a ANPOCS, das Ciências Sociais. Logo depois dela, no mesmo ano, foi a vez da ANPEd.

A criação da entidade da área da educação partiu de projeto elaborado por grupo de trabalho formado por docentes-pesquisadores dos quatro programas de pós-graduação do Rio de Janeiro.

Em 1977, a ANPEd foi, então, juridicamente constituída pelos representantes de uma dúzia e meia de programas: 11 de universidades federais, os mais numerosos; três de universidades católicas; dois de universidades estaduais paulistas; e o Instituto de Estudos Avançados em Educação (IESAE), com a ambivalência entre o público e o privado que caracterizava a Fundação Getúlio Vargas.

Dos 17 programas fundadores da ANPEd, 13 eram de universidades públicas, quase todos situados nas capitais. As exceções eram Santa Maria e Campinas.

Desde então, o campo mudou nuns aspectos e manteve-se em outros.

Em balanço anterior, que fiz da área, formulei a hipótese de que a pós-graduação em educação desenvolveu-se, no Brasil, mais por força de seus vícios de origem do que de suas virtudes. Destaco alguns defeitos estruturais graves, que, a meu ver, persistem.

A improvisação curricular tem sido a regra. Os programas resultam da mera reunião de docentes possuidores dos títulos acadêmicos previstos pelas agências de fomento, sem um critério definido por projeto acadêmico prévio. Os projetos são textos justificadores dos arranjos pactuados. As disciplinas e outras ativi- dades são listadas em função do interesse imediato dos professores, inventando-se linhas de pesquisa a partir da simples justaposição de projetos, linhas nas quais a imaginação desempenha papel estratégico.

Verifica-se uma surpreendente polivalência entre os docentes na orientação de teses e dissertações, que tratam dos mais variados temas, impedindo a acumulação de conhecimentos no âmbito de cada programa. Em conseqüência, nem cada programa nem cada docente se dedica a determinados temas, mas oscila ao sabor de interesses momentâneos.

Exagero? Talvez, mas penso que esse quadro esboça o panorama realista de nossa área.

Não se pense que eu suponho existirem apenas forças endógenas na determinação desse panorama. Estou certo de que elas não atuariam com a mesma intensidade sem a indução das agências de fomento, ansiosas pela obtenção de resultados rápidos - especialmente a CAPES.

A contribuição dos programas para a bibliografia da área já não merece o entusiasmo que lhe dediquei. Com efeito, se continuam sendo produzidos bons trabalhos, na forma de livros e artigos, derivados de teses, dissertações e pesquisas realizadas por docentes dos programas, minha sensação é que, proporcionalmente, cresceu mais o número de textos irrelevantes, gerados apenas pela motivação de publicar. Assim, a versão brasileira do imperativo norte-americano "publicar ou perecer", incentivado pelas agências de fomento em seu viés quantitativista, leva à perda da qualidade média, de modo que os catálogos das editoras e os sumários das revistas acabam por espelhar tal situação.

Os diplomas de mestre e de doutor em educação continuam a ser procurados e são os de mais fácil aquisição dentre os oferecidos pelas instituições brasileiras de ensino superior. Sua procura cresceu muito em virtude da exigência da Lei de Diretrizes e Bases da Educação de 1996 para que o corpo docente de cada universidade tenha pelo menos um terço de seus membros com títulos de mestre ou de doutor. Lamentavelmente, a demanda por diplomas baratos foi a que mais cresceu, induzindo a criação de programas em 
universidades públicas e privadas, mas em nível decrescente de qualidade acadêmica.

A tendência principal de expansão da pós-graduação em educação resulta de novos programas privados situados em cidades do interior, que já constituem um quarto dos sócios institucionais da nossa entidade.

Que repercussões essa reconfiguração do campo e de seu quadro associativo acarretará para a atuação da entidade é questão difícil de dizer agora, mas não podemos elidir essa questão, sob pena de reforçar as práticas dissimulatórias tão comuns em nosso meio. Deixar de enfrentar essa questão é um erro tão grave quanto tratá-la com preconceito.

Diagnóstico elitista? Chamá-lo assim pode diminuir, momentaneamente, o desconforto, mas nada muda no objeto a que se refere.

Que fazer? Nada como a prática para substituir conjecturas por formulações concretas. Proponho, então, a retomada prática, não declamatória, de dois compromissos históricos da ANPEd.

O primeiro compromisso histórico, que proponho retomar, é com a qualidade da pós-graduação em educação. Não a qualidade estreita, aquela que resulta da mera aplicação de indicadores quantitativos, que tanto entusiasmam os tecnocratas. Não se trata, tampouco, da avaliação de cada programa para darlhes notas, atribuir-lhes ou retirar-lhes a credencial de emissores de diplomas com validade jurídica.

Trata-se, isto sim, de avaliar com objetividade a produção do conjunto dos programas da área de educação: as publicações dos docentes-pesquisadores, as teses e dissertações dos estudantes titulados, os currículos (ensino e pesquisa) efetivamente desenvolvidos, para além dos projetos e dos formulários Coletacapes.

Como fazer é um problema difícil, e não tem precedentes. Mas, estou confiante que descobriremos os procedimentos adequados depois de decidido o que queremos fazer.

O resultado da avaliação da produção da área do conjunto da área - poderá levar cada programa a reavaliar-se, assim como ajudar a própria ANPEd a elaborar políticas próprias e atuar sobre as políticas governamentais com base sólidas.
O segundo compromisso histórico, que proponho retomar, é com a autonomização do campo educacional, na linha traçada pelo Manifesto dos Pioneiros da Educação Nova, de 1932.

A autonomia relativa do campo educacional está hoje encolhendo por causa da ofensiva de certas entidades religiosas para exercerem o controle do currículo da educação básica no setor público, ofensiva esta que tem recebido respaldo de setores do magistério, de parlamentares e do público em geral. Esse controle vai do ensino religioso nas escolas públicas até o conteúdo das aulas de ciências e programas de saúde, passando pelos quadros do magistério.

A autonomização do campo educacional diante do campo religioso foi expresso com clareza e vigor nos documentos da ANPEd, que levaram à Carta de Goiânia, aprovada em 1986 na IV Conferência Brasileira de Educação, da qual a entidade foi co-patrocinadora. Na Carta de Goiânia foi inscrita a consigna laicidade no ensino público.

Lamentavelmente, as organizações religiosas, não todas, mas as hegemônicas, mobilizaram apoios políticos poderosos e lograram inscrever na Constituição Federal de 1988 o dispositivo da oferta do ensino religioso no ensino fundamental das redes públicas, em disciplina facultativa para os alunos, a ser ministrada dentro do horário de aulas.

Com o acirramento da crise econômica e dos conflitos sociais, desde a década passada, a religião virou uma panacéia, defendida, surpreendentemente, por religiosos e ateus. Um remédio para todos os males, que se pretende ministrar em doses amplas aos alunos das escolas públicas, como um mecanismo de controle individual e social supostamente capaz de acalmar os indisciplinados, de conter o uso de drogas, de evitar a gravidez precoce e as doenças sexualmente transmissíveis, apresentando-se, também, como a única base válida para a ética e a cidadania, como se fosse uma espécie de educação moral e cívica do bem.

Postula-se uma espécie de média ideológica, como se existisse um repertório de crenças comuns a todas as religiões, média essa que se pretende seja o conteúdo do ensino religioso inter ou supraconfessional, do- 
tado, então, de legitimidade para integrar o currículo da escola pública, mesmo no Estado laico.

Ora, o campo religioso é necessariamente marcado por disputas pela hegemonia que assume ora a versão suave da missão, ora a aliança ocasional chamada ecumenismo, mas que pode chegar à competição ostensiva, em diversos graus e com diversas conseqüências. No passado como no presente, as disputas religiosas levaram à guerra, ao terrorismo, à tortura e à censura. Para a escola pública não convém nenhuma versão dessa guerra dos deuses, isto é, dos grupos que disputam a hegemonia em nome de seus deuses.

Em nosso país, essa hegemonia chegou ao ponto de instituições religiosas exercerem uma verdadeira tutela sobre a moral coletiva - uma aberração! A vanguarda na luta contra essa tutela já foi dos educadores, mas ela pertence, hoje, aos movimentos de mulheres, que se batem, principalmente, pelos direitos reprodutivos. Para a vigência desses, como de todos os direitos humanos, os movimentos de mulheres já se deram conta de que a existência de um Estado efetivamente laico é condição essencial e inadiável.

Aliás, essa luta que hoje é das mulheres concerne a todos - aos homens tanto quanto às mulheres -, uma luta que deveria envolver, na linha de frente, os educadores, individual e coletivamente - envolver a ANPEd, portanto.

Não é uma luta fácil.

Sabemos como a Lei de Diretrizes e Bases da Educação de 1996 saiu torta, pela via senatorial, mas um ponto deve ser sublinhado no texto originalmente aprovado pelo Congresso Nacional: a proibição de uso de recursos públicos para o ensino religioso. Como sua antecessora de 1961. Sabemos, também, como o Congresso Nacional, em geral tão lento, atendeu célere ao apelo do presidente que a sancionou para que o artigo 33 fosse logo modificado, antes da visita do papa João Paulo II, de modo que suprimisse justamente aquela proibição. Em conseqüência, desde 1997, a disciplina ensino religioso passou a ser financiada pelos recursos públicos, direta e indiretamente.

Podendo, agora, receber salários e outras vantagens, os agentes das entidades religiosas penetram o magistério dos sistemas estaduais e municipais e a eles juntam-se docentes dos quadros existentes. Em alguns sistemas de ensino, as entidades religiosas obtiveram legislação que lhes garante poder de decisão sobre o destino funcional dos professores dessa disciplina, até mesmo de dispensá-los do serviço público, se perderem sua confiança.

Pois bem, os educadores que defendemos a laicidade no ensino público na Constituinte fomos, naquela ocasião, derrotados. Mas não fomos aniquilados. Aqui estamos presentes e nos manifestamos, agora, com novas alianças, que nos fornecem uma base social, que jamais foi tão ampla.

Essa manifestação concerne à ANPEd. A entidade não mudou a posição assumida na Carta de Goiânia. Defende, pois, oficialmente, o ensino público laico.

Para não ficarmos na defesa de princípios abstratos ou longínquos e irmos à luta, no plano da política prática, aqui vai uma sugestão para a ANPEd: desencadear campanha nacional pela desobrigação do ensino religioso para os alunos das escolas públicas. Que ele deixe de ser imposto, como se obrigatório fosse. Sempre que for oferecido pelas escolas públicas, que os pais e os alunos saibam que se trata de uma disciplina facultativa. E mais: que os pais e os alunos saibam que as escolas têm a obrigação de oferecer alternativa pedagogicamente significativa a essa disciplina. Aliás, algumas legislações estaduais já prevêem isso. Nada de jogar bola no pátio, nem permissão para voltar para casa mais cedo ou chegar mais tarde, mas, isto sim, reforço das disciplinas obrigatórias ou mesmo a oferta de facultativas, mas de real interesse educativo. Uma disciplina só é de fato optativa se houver alternativa válida para os alunos. Não é preciso mudar a Constituição Federal nem a Lei de Diretrizes e Bases da Educação, mas conceber e pôr em prática currículos menos tutelados.

Concluo pela evocação de um ex-presidente da ANPEd, o único falecido, que lembro justamente por sua presença viva na dignidade, na produção acadêmica desafiadora e instigante, na atuação teórica e prática: Neidson Rodrigues. 
Dele guardo a imagem nítida de quem soube reorientar sua trajetória quando a conjuntura, a consciência ou ambas o levaram da teoria para a prática e, de novo, para a teoria; da filosofia para a educação e, de novo, para a filosofia; da educação superior para a educação básica e, de novo, para a educação superior.

Homem de profunda formação religiosa, Neidson Rodrigues foi sincero e ostensivo defensor do ensino público laico. Educado numa confissão religiosa não hegemônica, ele sabia, não por ouvir dizer, mas por experiência própria, que só a laicidade do Estado e da escola pública garante a efetiva liberdade, tanto para os crentes, de qualquer crença, quanto para os não-crentes, liberdade essa que é condição essencial para a efetivação de um dos direitos humanos fundamentais.

Recebido em outubro de 2007 Aprovado em novembro de 2007 